Marker Proteins in Inflammation Volume 2 



\section{Marker Proteins in Inflammation}

Volume 2

Proceedings of the

Second Symposium

Lyon, France, June 27 - 30, 1983

Editors

P. Arnaud · J. Bienvenu · P. Laurent

$W$
$\mathrm{DE}$
$\mathrm{G}$

Walter de Gruyter - Berlin · New York 1984 


\section{Editors}

Philippe Arnaud, Ph. D., M.D.

Department of Basic and Clinical

Immunology and Microbiology

Medical University of South Carolina

171 Ashley Road

Charleston, South Carolina 29403

U.S.A.

Jacques Bienvenu, M.D.

Biochemical Laboratory

Hópital Jules Courmont

F-69310 Pierre Bénite

France

Philippe Laurent, M.D.

Department of Immunology

Institut Pasteur de Lyon

77, Rue Pasteur

F- 69365 Lyon Cedex 2

France

CIP-Kurztitelaufnahme der Deutschen Bibliothek

Marker proteins in inflammation: proceedings of the ... symposium.

- Berlin ; New York : de Gruyter

Vol. 2. Proceedings of the second symposium, Lyon, France,

June $27-30,1983 .-1984$.

ISBN 3-11-009872-5

\section{Library of Congress Cataloging in Publication Data}

Main entry under title:

Marker proteins in inflammation, volume 2.

Proceedings of the "Second Symposium sur les marqueurs de I'inflammation," sponsored by the Groupe d'étude et de recherche sur les marqueurs de l'inflammation (GERMI)

Bibliography: $p$.

Includes indexes.

1. Inflammation--Congresses. 2. Proteins--Congresses.

I. Arnaud, P. (Philippe) II. Bienvenu, J. (Jacques), 1950- . .III. Laurent, P. (Philippe), 1949- . IV. Symposium sur les marqueurs de l'inflammation (2nd : 1983 : Lyon, France) V. Groupe d'étude et de recherche sur les marqueurs de l'inflammation (France) [DNLM: 1. Blood Proteins--diagnostic use--congresses. 2. Blood Proteins-immunology--congresses. 3. Inflammation--congresses. QZ 150 M345 1983] RB131.M353 $1984 \quad 616^{\prime} .0473 \quad 84-9462$ ISBN 3-11-009872-5

Copyright (c) 1984 by Walter de Gruyter \& Co., Berlin 30.

All rights reserved, including those of translation into foreign languages. No part of this book may be reproduced in any form - by photoprint, microfilm or any other means nor transmitted nor translated into a machine language without written permission from the publisher. Printing: Gerike GmbH, Berlin. - Binding: Dieter Mikolai, Berlin. Printed in Germany. 